\title{
PSA Nadir and Time to PSA Nadir Following Androgen Deprivation Therapy are the Predictors for Castration-Resistant Prostate Cancer in Patients with Metastatic Prostate Cancer
}

\author{
Yasinthorn Isaraworawanich, Teerayut Tangpaitoon, Dollacha Vanichakarn, Patranuch Noppakulsatit*
}

Division of urology, Department of surgery, Thammasat university hospital, Pathum Thani, Thailand

\begin{abstract}
Purpose: To evaluate the influence of nadir prostate-specific antigen (PSA) level and time to PSA nadir following androgen deprivation therapy (ADT)on disease progression of castration-resistant prostate cancer (CRPC) in patients with metastatic, hormone-sensitive prostate cancer (mHSPC).
\end{abstract}

Patients and methods: A total of 90 patients with metastatic, hormone-sensitive prostate cancer treated with androgen deprivation therapy in our hospital were included in our retrospective study. Patients' characteristics, PSA at PADT initiation (initial PSA), PSA nadir, TTN, follow up time, CRPC event were analyzed using Kaplan-Meier analysis and Cox regression model.

Results: At a median follow-up of 12 months, 57 patients (63.3\%) showed disease progression of CRPC Both PSA nadir and time to PSA nadir (TTN) was independent and significant predictors of CRPC event. Patients with higher PSA nadir ( $\geq 0.2 \mathrm{ng} / \mathrm{dL}$ ) and shorter time to PSA nadir (TTN $<6$ months) had significant shorter time to CRPC. Meanwhile, the Gleason score, age and initial PSA werenot significant predictors of disease progression. In the combined analyses showed patients with higher of PSA nadir and shorter TTN had significantly higher risk for CRPC event compared to lower PSA nadir and longer TTN (HR 69.243, p-value< 0.001)

Conclusion: We concluded that both higher PSA nadir and shorter time to PSA nadir are significant predictors of CRPC in patients with metastatic, hormone-sensitive prostate cancer receiving ADT.

Keywords: Metastatichormone sensitive prostate cancer, Androgen deprivation therapy, Time to PSA nadir, PSA nadir, Castration resistant prostate cancer

\section{Introduction}

Androgen-deprivation therapy (ADT) is the most effective systemic therapy in patients who have hormone-sensitive prostate cancer. PSA levels remain low or undetectable for years. ${ }^{1}$ However, the emergence of castration-resistant prostate cancer (CRPC) is typical. ${ }^{2}$ Treatment options for CRPC remain limited and the prognosis of patient with CRPC is dismal. ${ }^{3}$ With hormone treatment

of advanced prostate cancer, PSA level increases 6 to 12 months before definitive radiological or clinical of disease progression. ${ }^{4-7}$ Median survival in patients with CRPC is approximately 24 to36months. ${ }^{1}$ The accurate prediction parameter of disease progression might be used to evaluate prognosis of disease and benefit from aggressive or novel treatment. PSA kinetics have been used
Quick Response Code:

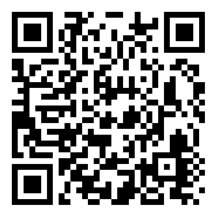

*Corresponding author: Patranuch Noppakulsatit, Division of urology, Department of surgery, Thammasat university hospital, Pathum Thani, Thailand

Received: 30 November, 2020

Published: 13 January, 2021

Citation: Yasinthorn I, Teerayut T, Dollacha V, Patranuch N. PSA Nadir and Time to PSA Nadir Following Androgen Deprivation Therapy are the Predictors for Castration-Resistant Prostate Cancer in Patients with Metastatic Prostate Cancer. Trends Uro Nephro Res. 2021;1(1):1-5. DOI: 10.53902/TUNR.2021.01.000504 
as useful prognostic indicators for disease or survival in different clinical setting including radical prostatectomy and external beam radiation therapy. ${ }^{8-11}$ Nevertheless, its prognostic ability for those receiving ADT for metastatic, hormone-sensitive prostate cancer is not well understood. The PSA nadir has been suggested to be the most significant predictor of progression to CRPC in many studies. ${ }^{12-17}$ However, the time to PSA nadir (TTN) is still controversy. Some earlier studies suggested that shorter TTN correlated with longer time of progression-free survival. ${ }^{4,5,18-20}$ But many recent studies suggested that longer TTN correlated with longer time of progression-free survival. ${ }^{1,16,17,21,22}$ In our study, we retrospectively reviewed our single-center treatment of metastatic-hormone sensitive prostate cancer (mHSPC) patients to evaluate the prognostic ability of PSA nadir and TTN in both individual and interactive effect on disease progression to CRPC.

\section{Materials and methods}

As a retrospective cohort study. The database in Thammasat university hospital between July 2012 and December 2019. A total of 90 patients who diagnosed metastatic-hormone sensitive prostate cancer and received androgen-deprivation therapy (ADT) such as gonadotropin-releasing hormone (GnRH) agonist plus anti-androgen, GnRH antagonist or bilateral orchiectomy were included in this study. GnRHagonist combined with anti-androgen were used in 23 patients (25.5\%), GnRH antagonist was used in 20 patients $(22.2 \%)$ and bilateral orchiectomy was used in 47 patients (52.2\%). Patients were followed up a progression of disease by PSA every 3 months thereafter. We determined the study size by using a hazard ratio $=4.3,{ }^{21} \mathrm{CRPC}$ event $=30 \%$, Patients who loss to follow-up $=10 \%$, power $80 \%, p=0.05$ and two-sided test. We found that the study size was 42 patients. Predictors used in multivariate analysis (Cox's proportional hazard model) were Gleason score, initial PSA, PSA nadir, TTN (add 10 patients per predictor). Thus, the study size was appropriately at least 82 patients.

Patients' characteristic was explained by age, BMI, Gleason score, PSA at ADT initiation (initial PSA), PSA nadir, TTN, follow up time, CRPC event.The PSA nadir was defined as the lowestPSA value achieved during ADT. Time to PSA nadir (TTN) was defined as the duration of time after initiation of ADT to the date of PSA nadir.

The disease progression of castration-resistant prostate cancer (CRPC) was definedas Conford et al., EAU guideline 2017.23

A serum testosterone level $<50 \mathrm{mg} / \mathrm{dl}$ or $1.7 \mathrm{nmol} / \mathrm{L}$ plus one of the following symptoms:

1. Biological progression.

I. Three consecutive rises in PSA 1 week apart, resulting in two $50 \%$ increases over the nadir, and PSA level $>2 \mathrm{ng} / \mathrm{mL}$.

2. Radiographic progression.

I. Two or more new bone metastases on bone scan.

II. The development of soft tissue lesions.
Patients were dichotomized according to median value, except for PSA nadir. The reasonable PSA nadir which measured by ROC curve was $0.8 \mathrm{ng} / \mathrm{ml}$ (cut point between sensitivity $70.18 \%$ and specificity $63.64 \%$ ). But we used PSA nadir $0.2 \mathrm{ng} / \mathrm{ml}$ because it seems to be an undetectable PSA and some previous studies reported that was correlated with disease progression and prostate cancer specific survival. ${ }^{1,3,16,17,22}$ Moreover, after we compared the AUC between PSA nadir $0.2 \mathrm{ng} / \mathrm{ml}$ and $0.8 \mathrm{ng} / \mathrm{ml}$. There was no statistically significant $(\mathrm{p}=0.63$ ) (Figure 1$)$. Meanwhile, the reasonable time to PSA nadir (TTN) which measured by ROC curve was 8 months (cut point between sensitivity $78.95 \%$ and specificity $81.82 \%$ ). Nevertheless, we used the median TTN (6 months) because this was suitable for follow up any patients and the AUC between TTN 6 months and 8 months were no statistically significant $(p=0.90)$ (Figure 2). Categorized patients into four groups: (1) PSA nadir $<0.2 \mathrm{ng} / \mathrm{ml}$ and TTN $\geq 6$ months (2) PSA nadir $<0.2 \mathrm{ng} / \mathrm{ml}$ and TTN $<6$ months (3) PSA nadir $\geq 0.2 \mathrm{ng} / \mathrm{ml}$ and TTN $\geq 6$ months (4) PSA nadir $\geq 0.2 \mathrm{ng} / \mathrm{ml}$ and TTN $<6$ months.

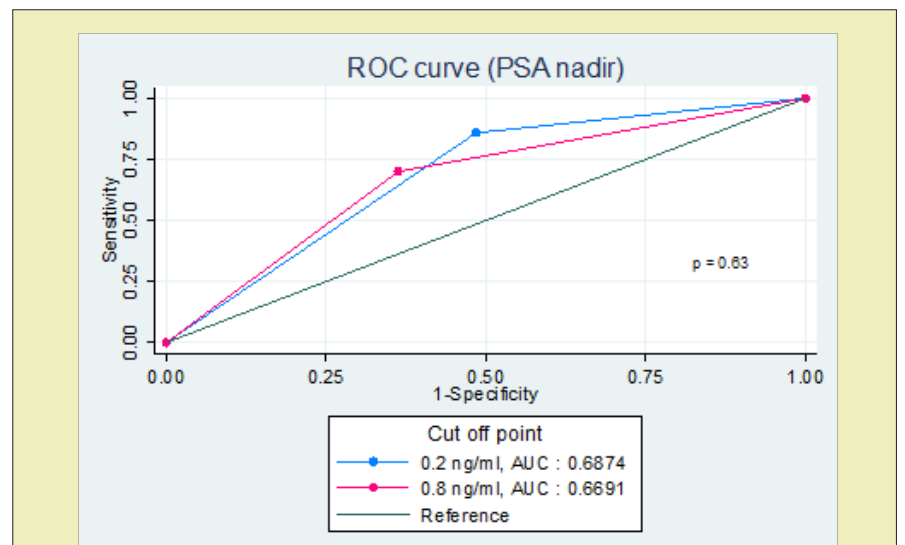

Figure 1: ROC Curve (PSA nadir).

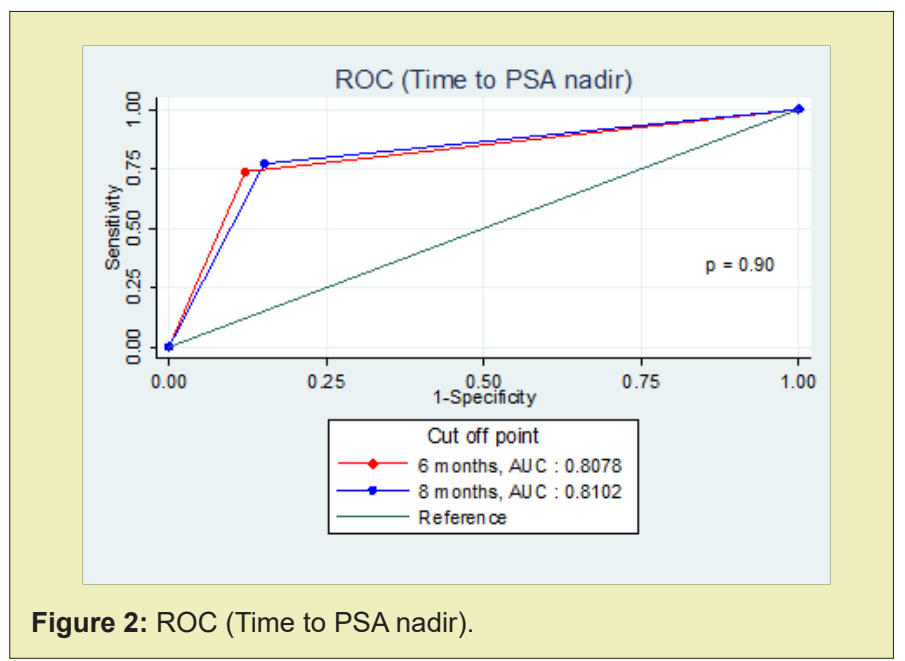

Kaplan-Meier analysis was used to evaluate progression-free survival. Univariate and multivariate analysis were used by Cox regression modelwere used to evaluate the associations of PSA nadir level and time to PSA nadir with CRPC event. All statistical analyses 
were used by STATA ver 15 . Values of $\mathrm{p}<0.05$ were considered to be statistically significant in all of the analyses.

\section{Results}

Patients' characteristics were explained as Table 1. At the date of ADT initiation, the median age was 72.5 year-old and median initial PSA level was $100 \mathrm{ng} / \mathrm{ml}$. Most common type of ADT was a bilateral orchiectomy. Gleason score $\geq 8$ was predominant (75.5\%). After ADT initiation, the median PSA nadir was $0.91 \mathrm{ng} / \mathrm{ml}$. Median time to PSA nadir was 6 months and median follow-up time was 12 months. 23 in 90 patients (25.5\%) were achieved a PSA nadir $<0.2 \mathrm{ng} / \mathrm{ml}$. 57 patients (63.3\%) had a progression of CRPC.

Table 1: Characteristics of the 90 patients who underwent ADT.

\begin{tabular}{|c|c|}
\hline \multicolumn{2}{|c|}{ Characteristics } \\
\hline At ADT initiation & Value \\
\hline Age (yr) & $72.5(53-90)$ \\
\hline BMI & $100(10-6480)$ \\
\hline \multicolumn{2}{|c|}{ Gleason score } \\
\hline 6 & $2(2.2)$ \\
\hline 7 & $20(22.2)$ \\
\hline 28 Type of ADT \\
\hline \multicolumn{2}{|c|}{$68(75.5)$} \\
\hline 1. GnRH agonist + anti-androgen & $23(25.5)$ \\
\hline 2. GnRH antagonist & $20(22.2)$ \\
\hline 3. Orchiectomy & $47(52.2)$ \\
\hline Nadir PSA (ng/ml) & $0.91(0-380)$ \\
\hline PSA nadir < 0.2 ng/ml & $23(25.5)$ \\
\hline PSA nadir $\geq 0.2 \mathrm{ng} / \mathrm{ml}$ & $67(74.5)$ \\
\hline Time to PSA nadir (months) & $6(1-41)$ \\
\hline Follow-up time (months) & $12(1-69)$ \\
\hline \multicolumn{2}{|c|}{ CRPC event } \\
\hline Yes & $57(63.3)$ \\
\hline No & $33(36.6)$ \\
\hline
\end{tabular}

Themedian progression-free survival in patients with $\mathrm{PSA}<0.2 \mathrm{ng} / \mathrm{ml}$ was significantly longer than those in patients with PSA nadir $\geq 0.2 \mathrm{ng} / \mathrm{ml}$ (60months vs. 11 months, $\mathrm{p}<0.001$ )(Figure 3 , Table 2). The median progression-free survival in patients with time to PSA nadir (TTN) $\geq 6$ months was significantly longer than those in patients with TTN $<6$ months. (42 months vs. 9 months, $\mathrm{p}<0.001$ )(Figure 4, Table 3). In combined analyses of PSA nadir and TTN, patients with PSA nadir $\geq 0.2 \mathrm{ng} / \mathrm{ml}$ and $\mathrm{TTN}<6$ months had the worst progression-free survival. In contrast to patients with PSA nadir $<0.2 \mathrm{mg} / \mathrm{ml}$ and TTN $\geq 6$ months had the best progression-free survival (Figure 5). In univariate analysis, Gleason score $\geq 8$, PSA nadir $\geq 0.2 \mathrm{ng} / \mathrm{ml}$, TTN $<6$ months were associated with worse progression-free survival (Table 4). In multivariate analysis, Gleason score was not a significant predictor of disease progression to CRPC. However, PSA nadir and TTN were remained significant predictors of disease progression to CRPC (hazard ratio [HR] 5.18 and 12.6, $\mathrm{p}<0.001$ respectively)(Table 5; Model 1). In combined analyses, patients with higher PSA nadir $(\geq 0.2 \mathrm{ng} / \mathrm{ml})$ andshorter TTN ( $<6$ months) had the worst progression-free survival (hazard ratio [HR], 69.243; $\mathrm{p}<0.001$ ) compared to those with lower PSA $(<0.2 \mathrm{ng} / \mathrm{ml})$ and longer TTN ( $\geq 6$ months)(Table 5;Model 2). Gleason score, initial PSA and ageat date of diagnosis were not independent predictors of disease progression to CRPC.

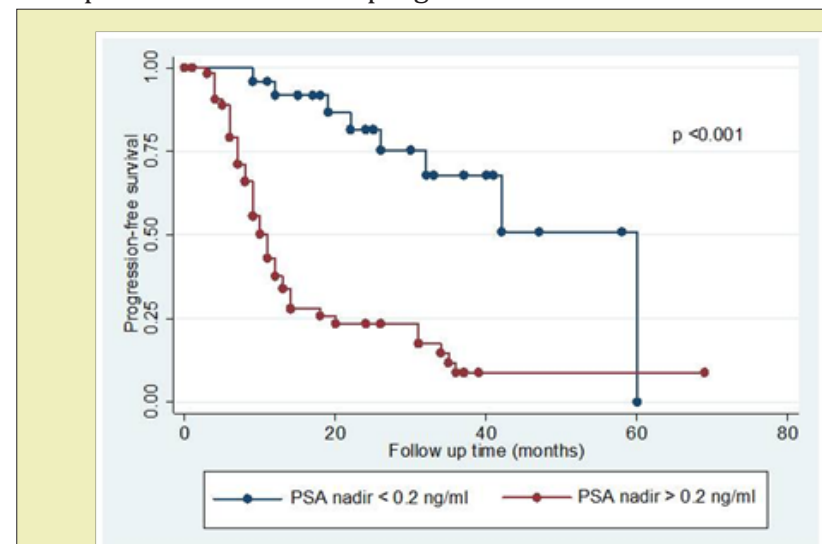

Figure 3

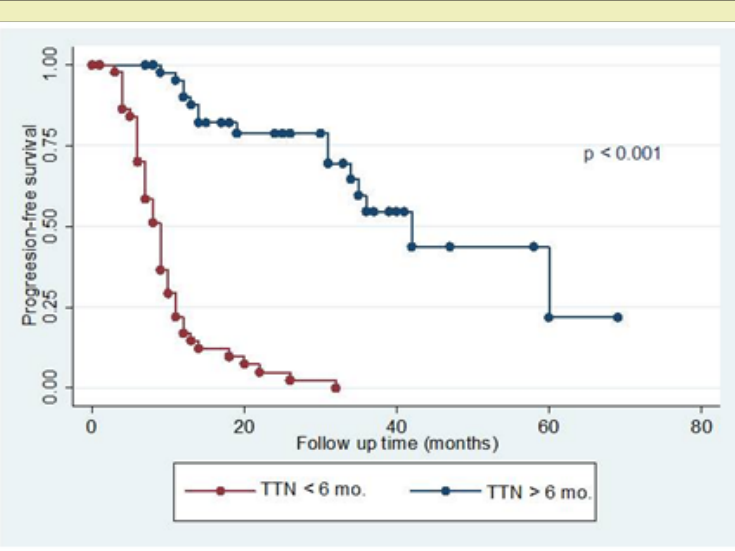

Figure 4

Table 2: Median progression-free survival for PSA nadir.

\begin{tabular}{|c|c|}
\hline Variable & Median PFS (months) \\
\hline PSA nadir $<0.2 \mathrm{ng} / \mathrm{ml}$ & 60 \\
\hline PSA nadir $\geq 0.2 \mathrm{ng} / \mathrm{ml}$ & 11 \\
\hline
\end{tabular}

Table 3: Median progression-free survival for TTN.

\begin{tabular}{|c|c|}
\hline Variable & Median PFS (months) \\
\hline TTN $<6$ months & 9 \\
\hline TTN $\geq 6$ months & 42 \\
\hline
\end{tabular}

Table 4: Univariate analyses of Cox proportional hazards regression analyses for progression-free survival.

\begin{tabular}{|c|c|c|}
\hline \multirow{2}{*}{ Variable } & \multicolumn{2}{|c|}{ Progression-free survival } \\
\cline { 2 - 3 } & HR (95\% CI) & p-value \\
\hline $\begin{array}{c}\text { Age at PADT initiation }(<75 \text { yr vs. } \\
\geq 75 \text { yr. })\end{array}$ & $1.103(0.640-1.902)$ & 0.724 \\
\hline Gleason score $(<7$ vs. $\geq 7)$ & $2.000(1.022-3.916)$ & 0.043 \\
\hline
\end{tabular}




\begin{tabular}{|c|c|c|}
\hline $\begin{array}{c}\text { Initial PSA }(<100 \mathrm{ng} / \mathrm{ml} \text { vs. } \\
\geq 100 \mathrm{ng} / \mathrm{ml})\end{array}$ & $1.408(0.769-2.577)$ & 0.267 \\
\hline $\begin{array}{c}\text { PSA nadir }(<0.2 \mathrm{ng} / \mathrm{ml} \text { vs. } \\
\geq 0.2 \mathrm{ng} / \mathrm{ml})\end{array}$ & $5.291(2.470-11.334)$ & $<0.001$ \\
\hline TTN $(\geq 6$ mo. vs. $<6$ mo. $)$ & $12.962(6.256-26.860)$ & $<0.001$ \\
\hline
\end{tabular}

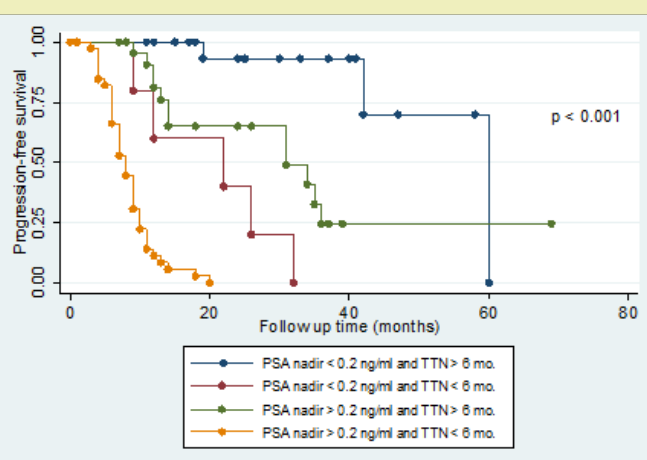

Figure 5

Table 5: Multivariate analyses of Cox proportional hazards regression analyses for progression-free survival.

\begin{tabular}{|c|c|c|}
\hline \multirow{2}{*}{ Variable } & \multicolumn{2}{|c|}{ Progression-free survival } \\
\cline { 2 - 3 } & HR (95\% CI) & p-value \\
\hline $\begin{array}{c}\text { Age at PADT initiation }(<75 \mathrm{yr} \\
\text { vs. } \geq 75 \text { yr. }\end{array}$ & $0.962(0.547-1.692)$ & 0.892 \\
\hline $\begin{array}{c}\text { Gleason score (<7vs. } \geq 7) \\
\text { Initial PSA (<100ng/ml vs. } \\
\geq 100 \mathrm{ng} / \mathrm{ml})\end{array}$ & $1.115(0.564-2.206)$ & 0.754 \\
\hline $\begin{array}{c}\text { PSA nadir (<0.2ng/ml vs. } \geq \\
0.2 \mathrm{ng} / \mathrm{ml})\end{array}$ & $5.180(2.236-11.998)$ & $<0.001$ \\
\hline TTN $(\geq 6 \mathrm{mo} . \mathrm{vs.}<6 \mathrm{mo})$. & $12.663(5.741-27.933)$ & $<0.001$ \\
\hline Model 2. & $1($ Reference) & - \\
\hline$<0.2 \mathrm{ng} / \mathrm{ml} / \geq 6 \mathrm{mo}$. & $15.818(3.480-71.903)$ & $<0.001$ \\
\hline$<0.2 \mathrm{ng} / \mathrm{ml} /<6 \mathrm{mo}$. & $5.430(1.504-19.560)$ & 0.01 \\
\hline$\geq 0.2 \mathrm{ng} / \mathrm{ml} / \geq 6 \mathrm{mo}$. & $69.243(17.791-269.494)$ & $<0.001$ \\
\hline$\geq 0.2 \mathrm{ng} / \mathrm{ml} /<6 \mathrm{mo}$. & & \\
\hline
\end{tabular}

\section{Discussion}

Although PSA kinetic including PSA nadir level and TTN are useful indicators for evaluating the response to ADT, a prognostic significance these PSA parameters is still controversial. The optimal threshold of PSA nadir were different in each study, e.g., Hussain et al. ${ }^{24}$ Reported that PSA nadir $<4 \mathrm{ng} / \mathrm{ml}$. . Whereas Kwak et al. ${ }^{15}$ and Miller et al. ${ }^{13}$ showed that PSA nadir level of 1.1 and $4 \mathrm{ng} / \mathrm{ml}$ were optimal threshold for predicting the progression to CRPC, respectively. However, in many other studies suggested that PSA nadir of $0.2 \mathrm{ng} / \mathrm{ml}$ was the optimal PSA threshold for predicting the disease progression to CRPC. ${ }^{1,3,16,17,22}$ In patients with PSA nadir threshold after receiving ADT were failure to achieve a level of $0.2 \mathrm{ng} / \mathrm{ml}$, they were associated with a 20 times likelihood of disease progression to CRPC. ${ }^{16}$ Hence, in our study, we used the PSA nadir threshold of $0.2 \mathrm{ng} / \mathrm{ml}$ and it showed that lower PSA threshold $(<0.2 \mathrm{ng} / \mathrm{ml})$ after ADT was an independent predictor of longer disease progression to CRPC. Our study support many previous studies.
The prognostic ability of time to PSA nadir level (TTN) after ADT on disease progression is still controversial. In many earlier studies were showed that the shorter TTN was associated with longer time to disease progression. ${ }^{4,5,18}$ In contrast to many recent studies were reported thatshorter TTN was associated with shorter time to disease progression. ${ }^{1,16,17,21,22}$ For example;Choueiri et al.,Huang et al., and Sasaki et al. suggested that longer TTN after ADT associated with longer progression-free or overall survival. ( $\geq 6$ months, $\geq 10$ months and $\geq 9$ months, respectively). In our study support these recent studies. The shorter TTN ( $<6$ months) after ADT was an independent predictor of shorter disease progression to CRPC in univariate and multivariate analysis. Furthermore, in the combined analysis of PSA nadir and TTN, patients withPSA nadir $\geq 0.2 \mathrm{ng} / \mathrm{ml}$ and TTN $<6$ months had the worst progression-free survival compared with PSA nadir $<0.2 \mathrm{ng} / \mathrm{ml}$ and TTN $\geq 6$ months (HR, 69.243, $\mathrm{p}<0.001$ ).

The hypothesis of our results can be possibly explained by many recent studies. The rapid reduction of PSA after ADT may affect by downregulation of androgen receptor rather than prostate cancer cell death and an adequate environment for growing castration-resistant prostate cancer cells might be induced by a rapid removal of hormone-sensitive prostate cancer cells. ${ }^{22}$ Furthermore, the quick suppression of androgen receptor during ADT may have a negative impact on disease progression, because androgen receptor can act as tumor suppressor for the prostate cancer. ${ }^{17}$ In this study, we recognized several limitations. First, this study had a small population. We need the larger population to confirm our results. Second, the initial PSA in many patients were reported $\geq 100 \mathrm{ng} / \mathrm{ml}$ because the laboratory department did not dilute to the exact value.

\section{Conclusion}

We concluded that higher PSA nadir and shorter TTN after ADT were the higher risk for castration-resistant prostate cancer in patients with metastatic-hormone sensitive prostate cancer. These might be helpful for decision making in early aggressive treatment strategy such as chemotherapy or novel therapy.

\section{Acknowledgments}

None.

\section{Conflicts of interest}

None.

\section{References}

1. Choueiri TK, Xie W, D'Amico AV, et al. Time to prostate-specific antigen nadir independently predicts overall survival in patients who have metastatic hormone-sensitive prostate cancer treated with androgendeprivation therapy. Cancer. 2009;115(5):981-987.

2. Taplin ME. Drug insight: role of the androgen receptor in the development and progression of prostate cancer. Nature clinical practice Oncology. 2007;4(4):236-244.

3. Hori S, Jabbar T, Kachroo N, et al. Outcomes and predictive factors for biochemical relapse following primary androgen deprivation therapy in men with bone scan negative prostate cancer. Journal of cancer research and clinical oncology. 2011;137(2):235-241.

4. Arai Y, Yoshiki T, Yoshida O. Prognostic significance of prostate specific antigen in endocrine treatment for prostatic cancer. J Urol. 1990;144(6):1415-1419. 
5. Cooper EH, Armitage TG, Robinson MR, et al. Prostatic specific antigen and the prediction of prognosis in metastatic prostatic cancer. Cancer. 1990;66(5 Suppl):1025-1028.

6. Mulders PF, Fernandez del Moral P, Theeuwes AG, et al. Value of biochemical markers in the management of disseminated prostatic cancer. Eur Urol. 1992;21(1):2-5.

7. Denis LJ, Carnelro de Moura JL, Bono A, et al. Goserelin acetate and flutamide versus bilateral orchiectomy: a phase III EORTC trial (30853). EORTC GU Group and EORTC Data Center. Urology. 1993;42(2):119-129.

8. D'Amico AV, Chen MH, Roehl KA, et al. Preoperative PSA velocity and the risk of death from prostate cancer after radical prostatectomy. The New England journal of medicine. 2004;351(2):125-135.

9. D'Amico AV, Renshaw AA, Sussman B, et al. Pretreatment PSA velocity and risk of death from prostate cancer following external beam radiation therapy. JAMA. 2005;294(4):440-447.

10. Zhou P, Chen MH, McLeod D, et al. Predictors of prostate cancer-specific mortality after radical prostatectomy or radiation therapy. Journal of clinical oncology: official journal of the American Society of Clinical Oncology. 2005;23(28):6992-6998.

11. D’Amico AV, Whittington R, Malkowicz SB, et al. Biochemical outcome after radical prostatectomy, external beam radiation therapy, or interstitial radiation therapy for clinically localized prostate cancer. JAMA. 1998;280(11):969-674.

12. Ercole CJ, Lange $\mathrm{PH}$, Mathisen $\mathrm{M}$, et al. Prostatic specific antigen and prostatic acid phosphatase in the monitoring and staging of patients with prostatic cancer. J Urol. 1987;138(5):1181-1184.

13. Miller JI, Ahmann FR, Drach GW, et al. The clinical usefulness of serum prostate specific antigen after hormonal therapy of metastatic prostate cancer. J Urol. 1992;147(3 Pt 2):956-961.

14. Park YH, Hwang IS, Jeong CW, et al. Prostate specific antigen half-time and prostate specific antigen doubling time as predictors of response to androgen deprivation therapy for metastatic prostate cancer. J Urol. 2009;181(6):2520-2524.

15. Kwak C, Jeong SJ, Park MS, et al. Prognostic significance of the nadir prostate specific antigen level after hormone therapy for prostate cancer. J Urol. 2002;168(3):995-1000.
16. Morote J, Trilla E, Esquena S, et al. Nadir prostate-specific antigen best predicts the progression to androgen-independent prostate cancer. International journal of cancer. 2004;108(6):877-881.

17. Huang SP, Bao BY, Wu MT, et al. Impact of prostate-specific antigen (PSA) nadir and time to PSA nadir on disease progression in prostate cancer treated with androgen-deprivation therapy. The Prostate. 2011;71(11):1189-1197.

18. Petros JA, Andriole GL. Serum PSA after antiandrogen therapy. Urol Clin North Am. 1993;20(4):749-756.

19. Furuya Y, Akimoto S, Akakura K, et al. Response of prostate-specific antigen after androgen withdrawal and prognosis in men with metastatic prostate cancer. Urol Int. 1998;60(1):28-32.

20. Stamey TA, Kabalin JN, Ferrari M, Yang N. Prostate specific antigen in the diagnosis and treatment of adenocarcinoma of the prostate. IV. Antiandrogen treated patients. J Urol. 1989;141(5):1088-1090.

21. Hong SY, Cho DS, Kim SI, et al. Prostate-specific antigen nadir and time to prostate-specific antigen nadir following maximal androgen blockade independently predict prognosis in patients with metastatic prostate cancer. Korean journal of urology. 2012;53(9):607-613.

22. Sasaki T, Onishi T, Hoshina A. Nadir PSA level and time to PSA nadir following primary androgen deprivation therapy are the early survival predictors for prostate cancer patients with bone metastasis. Prostate cancer and prostatic diseases. 2011;14(3):248-252.

23. Cornford P, Bellmunt J, Bolla M, al. EAU-ESTRO-SIOG Guidelines on Prostate Cancer. Part II: Treatment of Relapsing, Metastatic, and Castration-Resistant Prostate Cancer. Eur Urol. 2017;71(4):630-642.

24. Hussain M, Tangen CM, Higano $C$, et al. Absolute prostate-specific antigen value after androgen deprivation is a strong independent predictor of survival in new metastatic prostate cancer: data from Southwest Oncology Group Trial 9346 (INT-0162). Journal of clinical oncology: official journal of the American Society of Clinical Oncology. 2006;24(24):3984-3990. 